\title{
DETECTION AND DISCRIMINATION OF THE THICK OIL PATCHES ON THE SEA SURFACE
}

\author{
Dominique Dubucq ${ }^{1, *}$, Guillaume $\operatorname{Sicot}^{2}$, Marc Lennon $^{3}$, Véronique Miegebielle ${ }^{1}$ \\ ${ }^{1}$ TOTAL E\&P - 64000 Pau - France - (dominique.dubucq, veronique.miegebielle)@ total.com \\ ${ }^{2}$ ENSTA - Bretagne, 29000 Brest - guillaume.sicot@ensta-bretagne.fr \\ ${ }^{3}$ SAS ACTIMAR - 29200 Brest - France - lennon@actimar.fr
}

Commission VIII, WG VIII/5

KEY WORDS: Oil slick thickness, offshore slick, SWIR, VNIR, optical multispectral data, hyperspectral characterization, reflectance spectra

\begin{abstract}
:
Detection of natural or accidental oil slick at sea surface is important both for exploration purposes and for environment protection. Radar imagery, either satellite or airborne is the prime tool to detect those slicks. Radar is widely used by the national agencies to monitor their maritime areas for accidental pollutions or boat discharges. Radar images can detect oil slick even in the presence of clouds. However the sea surface back scattered energy is rather insensitive to oil thickness. On the contrary several studies tend to prove that optical data may be used to estimate the oil thickness. These data may be in the form of hyperspectral data or thermal infrared data. The objective of this study is to show that SWIR satellite data which are more widely available than hyperspectral data, better resolved than thermal data and available at a very limited cost, can be used to detect and qualitatively assess the thickness of oil slicks. This is important to assess volumes of naturally release oil in the oceans and in case of a crisis to send intervention teams where oil is thickest.
\end{abstract}

\section{INTRODUCTION}

Detection of oil slicks is of prime importance for national agencies dealing with the protection of their coasts and environment. Natural oil seepages also of great interest for Oil\&Gas companies in their exploration for new producing areas: natural seepages are indicating the presence of mature source rock which is one of the key information in a new exploration area. Oil\&Gas companies are also keen to monitor the integrity of their own installations and in the case of undesired oil leak to send the intervention teams where they will have most impact, i.e. in the areas of thickest oil.

Being able to assess the oil thickness would also allow getting an estimate of oil much oil an oil system has generated.

The usual approach to detect oil slicks is to use radar imagery (Figures 5e and 5f). Oil at sea surface is damping the capillarity waves and therefore reducing the Bragg back scattering. As the result, oil at sea surface appears as black patches on radar images. However this damping mechanism is relatively insensitive to the oil thickness.

Some attempts have been made to detect thickness variations with polarimetric radar acquisitions (Minchew, 2012; Skrunes, 2012) but needs further validation.

In the case of an oil spill, thickness variations of the spill are mapped according to the 'Bonn Agreement Appearance Code'. This code is defining five different thickness classes ranging from $.04 \mu \mathrm{m}$ to $200 \mu \mathrm{m}$. The classification is based on the visual appearance of the slick.

To go beyond the $200 \mu \mathrm{m}$ thickness limit, Thermal InfraRed (TIR, 8-12 $\mu \mathrm{m}$ wavelengths) can discriminate oil from seawater by identification of thermal contrast spatial patterns. TIR oil slick detection works by identifying a contrast between the emissivity or temperature of the oil slick with the background, oil-free water.

During daytime, oil slicks thicker than $150 \mu \mathrm{m}$ appear warmer (i.e. brighter) than surrounding water. Thinner oil slicks appear cooler (i.e. darker). This reverses at night time with a $50-150$ $\mu \mathrm{m}$ transition (Fingas 1997). During daytime the thick dark slick absorbs the sun energy, while thin slicks are at the same temperature as the underlying water and appear cooler than water as a consequence of lower emissivity of oil compared to water (+/-0.96 vs +/- 0.98).

Satellites such as Landsat, or Aster, provide thermal bands with a resolution of 60 to $100 \mathrm{~m}$.

Work from Clark (Clark, 2010), Sicot (Sicot 2014) and others seem to indicate that the NIR-SWIR domains $(0.7-2.5 \mu \mathrm{m}$ wavelength) offer better opportunities to detect and characterize thick oil slicks. This paper will focus on this domain.

\section{OIL CHARACTERIZATION IN THE NIR-SWIR DOMAIN}

Clark (Clark, 2010) showed that the overall NIR-SWIR (700$2500 \mathrm{~nm}$ ) reflectance spectrum changes with oil thickness, and also emulsion rate.

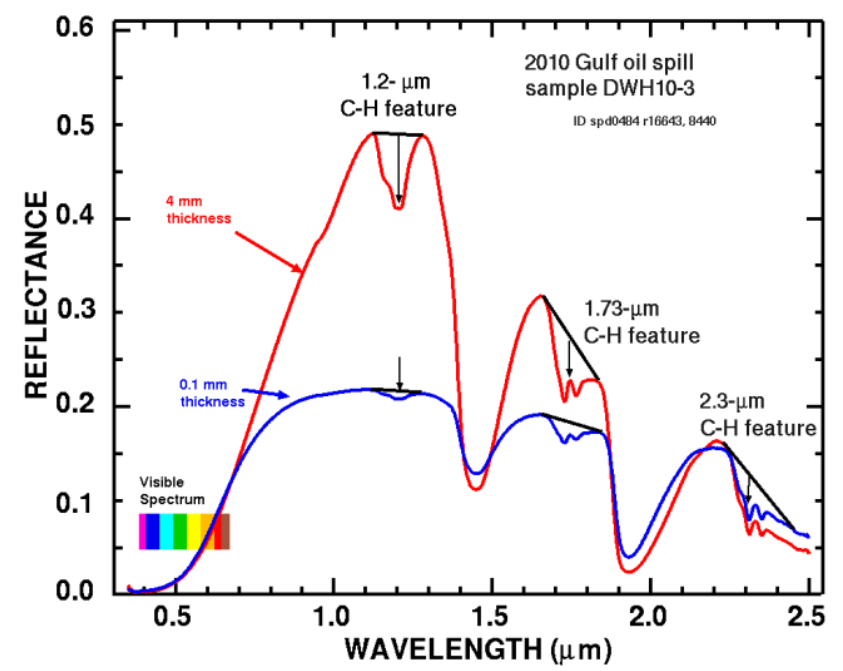


Figure 1. Laboratory spectra of oil emulsion from the Deepwater Horizon oil spill. From Clark, 2010

If the spectral resolution of the images is fine enough (a few nanometers) as with hyperspectral images, it is possible to compute very simple 'hydrocarbon indices' such as the Kuhn index (Kuhn, 2004) which corresponds to the depth of the 1.73 $\mu \mathrm{m}$ hydrocarbon absorption band. This band is preferred to the $1.2 \mu \mathrm{m}$ and $2.3 \mu \mathrm{m}$ absorption bands which are closer to water absorption bands (1.1 and $2.4 \mu \mathrm{m})$. Kokaly (Kokaly, 2010) uses a combination of normalized indices similar to the NDVI index used to detect the healthy vegetation. These indices are based either on radiances or reflectances near the $1.73 \mu \mathrm{m}, 1.2 \mu \mathrm{m}$ hydrocarbon absorption bands and the slope of the spectrum in the NIR domain $(0.7-1.0 \mu \mathrm{m})$.

This later approach is interesting. Images can be produced very rapidly that indicate the thick oil slick patches.

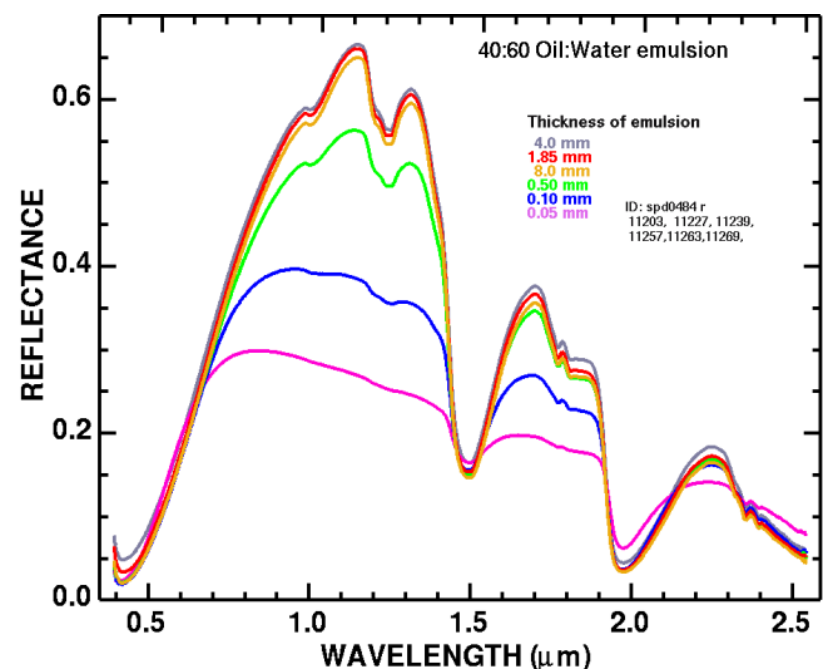

Figure 2: Reflectance spectra of 40:60, oil:water emulsion for a range of thicknesses (from Clark, 2010).

Figure 2 is showing that there is no much variations of the reflectance spectra above a certain thickness; Hence, Kokaly's indices will saturate above this thickness and may even decrease. But this thickness is in the $\mathrm{mm}$ or $\mathrm{cm}$ range depending on the oil and emulsion rate, compared to $200 \mu \mathrm{m}$ for the thickest class the Bonn code in the visible domain.

Kokaly's indices can be computed from reflectance spectra or luminance spectra. It is better to compute them from reflectance spectra as reflectance data can be more easily compared to lab measurements. However qualitatively, indices computed from radiance give very similar indication of the thickest hydrocarbon patches.

Kokaly's method is going toward simplification which is good as hyperspectral data acquisitions are expensive and requires specific sophisticated cameras. With Kokaly's method, a multispectral camera with the appropriate filters could be used; Luminances or reflectances at only six wavelengths are required. Therefore the hyperspectral camera could be replaced by a multispectral camera with the appropriate filters.
Of course, results will depend on the type of oil, and degree of emulsification, as can be seen on figure 3. Shapes are similar but amplitudes vary largely.

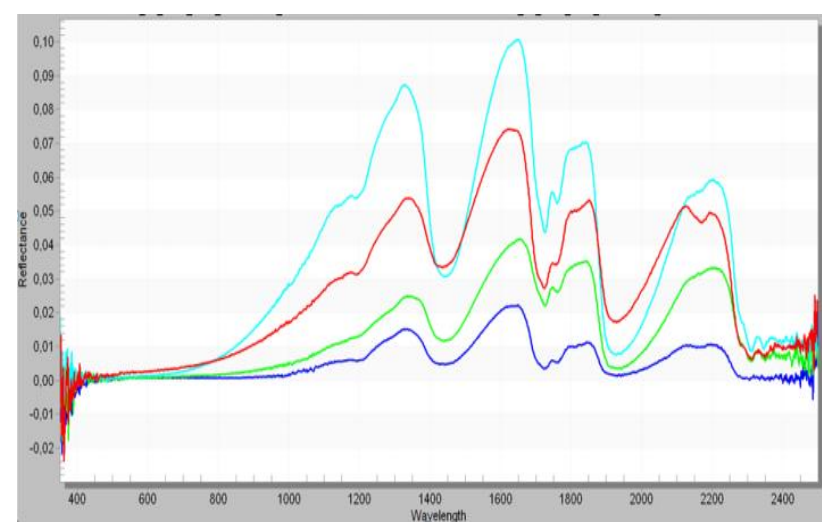

Figure 3: Reflectance spectra for four different crude oils from West Africa and North Sea, $1 \mathrm{~mm}$ thick.

$\mathrm{X}$ axis is wavelength, $\mathrm{Y}$ axis is reflectance value

To further simplify the approach, it may be noted that reflectance for the thick oil layers in the NIR and SWIR domain are larger than for the thin layers. Hence false color images with bands taken in the NIR, and SWIR bands, for example 1.2, 1.7 and $2.2 \mu \mathrm{m}$ should highlight the thick patches of oil.

\section{QUALITATIVE DETECTION OF THICK HYDROCARBONS}

\subsection{Multispectral data, oil spill}

Figure 4a show a true colour LANDSAT-7 image from the Deep Water Horizon accident on the $1^{\text {st }}$ of May 2010.

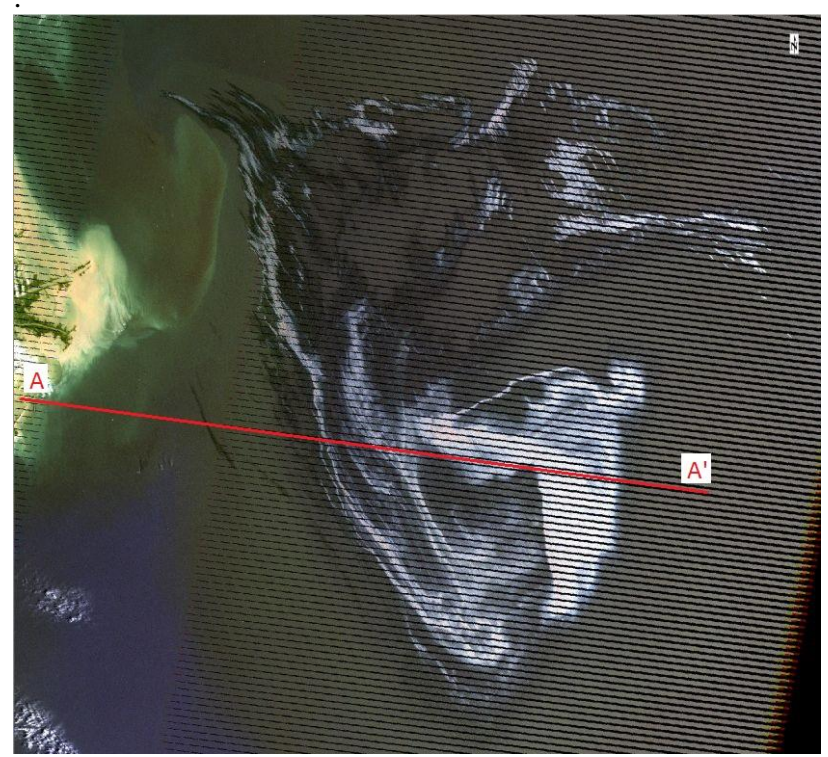

Figure 4a. Deep Water Horizon, $1^{\text {st }}$ May 2010, true colour LANDSAT7 image. The width of the image is about $90 \mathrm{~km}$.

Figure $4 \mathrm{~b}$ and $4 \mathrm{c}$ show the amplitudes for the true colours and for the SWIR/NIR bands along transect A-A' from Fig 4a. High amplitudes with respect to the oil-free water amplitude are believed to be areas of thicker oil. But the SWIR/NIR high amplitudes are restricted to a more limited extension than for the visible channels indicating that SWIR offers a better 
discrimination of thick oil patches than channels in the visible domain.

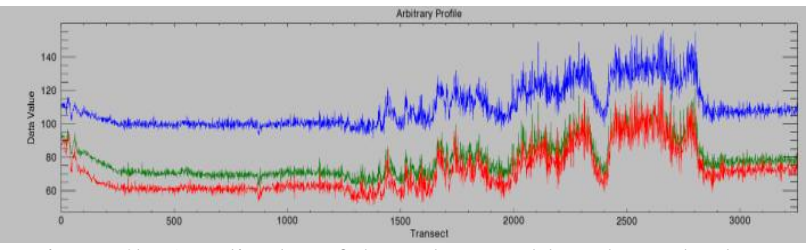

Figure 4b. Amplitudes of the red-green-blue channels along transect A-A' from figure $4 a$.

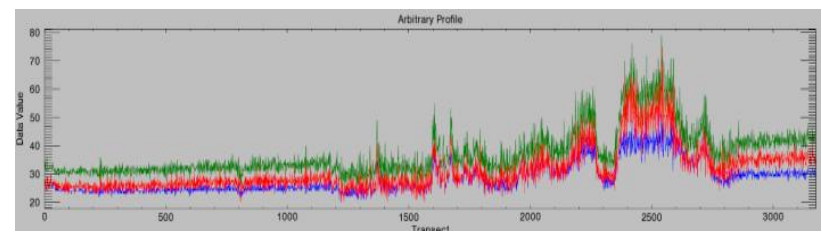

Figure 4c. Amplitudes of the SWIR-NIR channels along transect A-A' from figure 4a.

\subsection{LANDSAT Multispectral Data, natural seep}

The following figures are extracted from a LANDSAT-8 image taken over a giant oil field in Mexico that has been producing for decades and that is said to have been discovered by a fisherman who had noticed recurrent natural oil slicks at sea surface. All the images from Figures $5 \mathrm{a}$ to $5 \mathrm{f}$ cover the same area and are at the same scale.

Figure 5a is the true colour image of an area of the field with visible apparent facilities. The image was captured on the $24^{\text {th }}$ of March 2014. Area A is a recurrent oil slick away from the installations. The multiple impact points at sea surface appear in a white color, brighter than the surrounding oil-free water. Area $\mathrm{B}$ is an accidental pollution. Currents appear to be toward the WNW in particular from the shape of the natural oil slick. Wind is coming from the South-East from the direction of the smoke from the platform torches. With these current and wind, the oil spill tends to be thicker toward the NW.

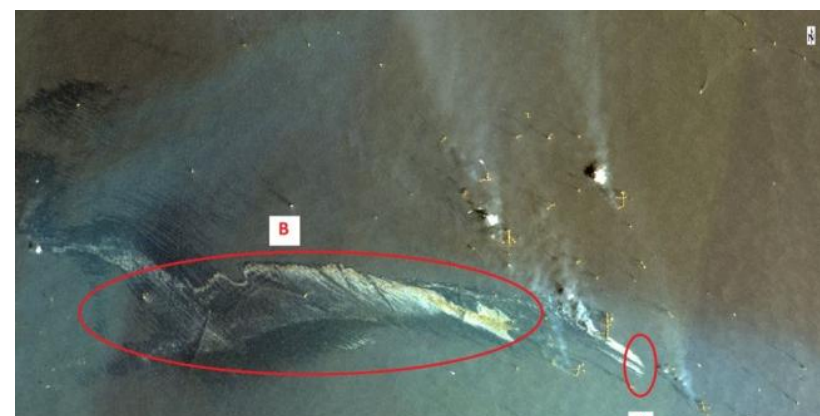

A

\section{$2 \mathrm{Km}$}

Figure 5a. Natural colour image of giant oil field with natural seepage in A and non recurrent oil spill in B. LANDSAT-8, $24^{\text {th }}$ March 2014

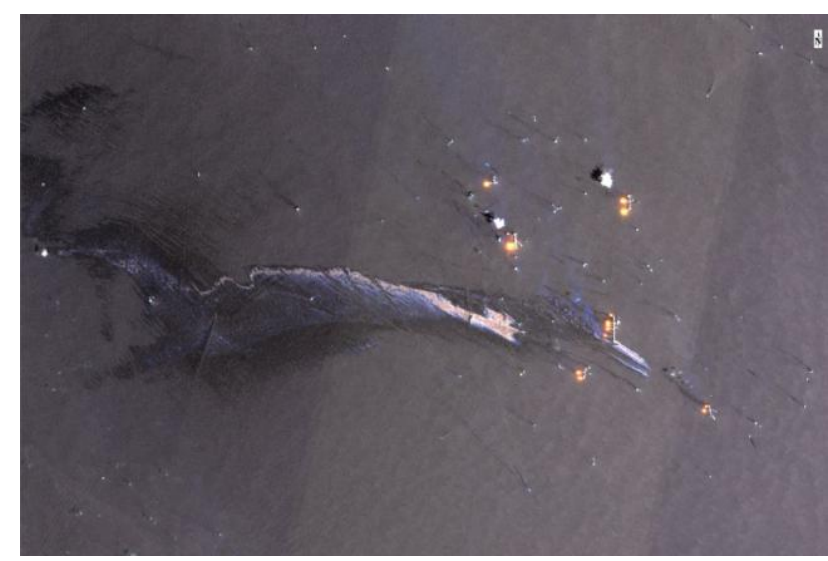

Figure 5b. False colour image of field in Fig; 5a. Channels are SWIR2, SWIR1 and NIR.

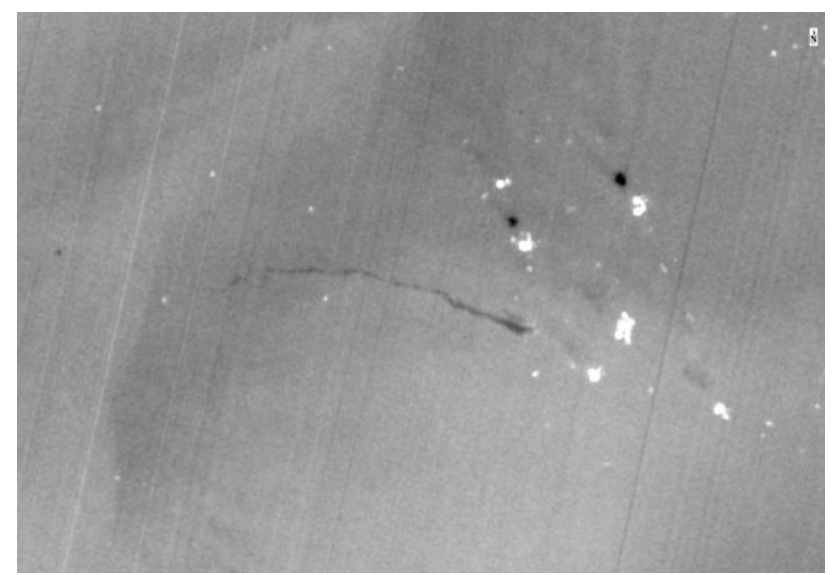

Figure 5c. Intensity image in the TIR domain of field from image $5 \mathrm{a}$.

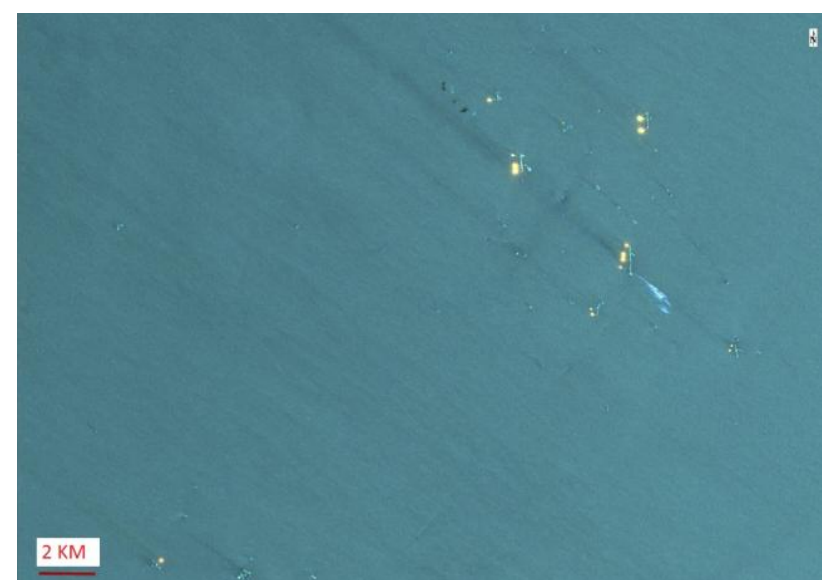

Figure 5d; same area, SWIR channels. LANDSAT-8, $12^{\text {th }}$ April 2015. Only the recurrent seep is visible.

Figure $5 \mathrm{~b}$ show a false colour images with red-green-blue channels being the SWIR2, SWIR1 and NIR channels from the LANDSAT image. As expected, the northern limit of the spill (area B) which is thicker appears brighter than the surrounding oil-free water. On the contrary, most of the spill is darker than surrounding waters, indicating sub-millimetric thickness.

Figure $5 c$, is the thermal infra-red channel TIR1 intensity. The oil spill is barely visible. Only the thickest part appears more cooler/darker than surrounding waters: resolution of the TIR channel is $100 \mathrm{~m}$ compared to $30 \mathrm{~m}$ for the visible and NIRSWIR channels. 
Figure 5d, is another image of the same area taken on the 12th April 2015. Only the recurrent seep is visible, brighter than the surrounding oil-free water.

Figures $5 \mathrm{e}$ and $5 \mathrm{f}$ are ENVISAT SAR images taken over the same area on the $20^{\text {th }}$ January 2004 and $30^{\text {th }}$ October 2011, showing the persistence over a long period of time of the natural seep but also the much larger extent seen by the radar image.

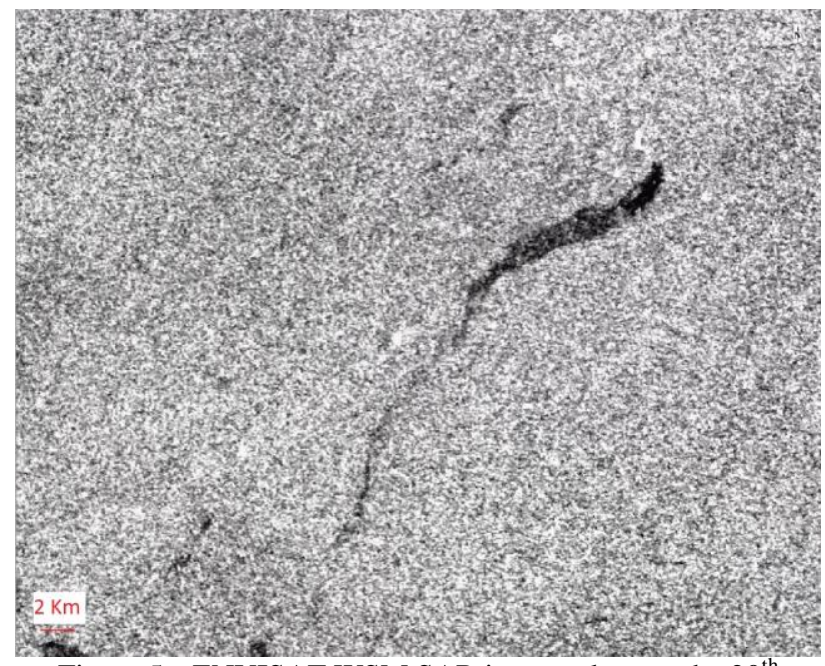

Figure 5e. ENVISAT WSM SAR image taken on the $20^{\text {th }}$

January 2004 on same area as Fig. 5a. Resolution is $150 \mathrm{~m}$.

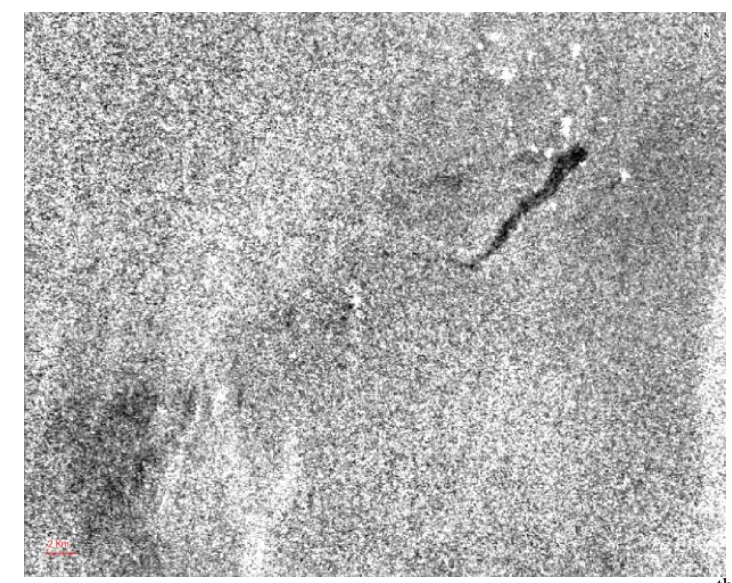

Figure 5f. ENVISAT WSM SAR image taken on the $30^{\text {th }}$ October 2011on same area as Fig. 5a .

\section{CONCLUSIONS}

Radar is the most common tool to detect oil slicks either natural or accidental. However Radar does not discriminate thin slicks (less than a few $\mu \mathrm{m}$ thick) than thicker slicks. Optical data in the visible domain can be used but do not discriminate patches thicker than $200 \mu \mathrm{m}$. Thermal infrared can discriminate patches thicker than $150 \mu \mathrm{m}$ but thermal sensors on satellites have low resolution. Finally Short Wave Infrared (SWIR) which has not been used much is able to discriminate $\mathrm{mm}$ to $\mathrm{cm}$ thick oil layers in the lab. Satellite image analysis confirms that only thick patches are highlighted by the SWIR wavelengths.

For exploration this will help reassess the volumes of naturally expulsed oil seeps, as SWIR images indicate that most natural seeps, worldwide, are thin. For environmental protection, SWIR images will help target interventions where oil is thicker. SWIR images are largely available with the LANDSAT and SENTINEL-2 satellites, at no cost, but also with satellites such as WV-3 at a very fine resolution and at a cost which will remain much lower than airborne hyperspectral acquisitions.

\section{REFERENCES}

Brekke, C, Kudryavtsev, V., Salberg, A.-B., Skrunes, S., Ermakov, S., Migliaccio, M. and Holt, B.: Current advances in SAR remote sensing of oil slicks and a look-ahead, Proc. SeaSAR 2012, Troms $\emptyset$, Norway, 12 pp., 2012

Clark, R., Swayze, G., Leifer, I., Livo, K., Kokaly, R., Hoefen, T.,Lundeen, S., Eastwood, M., Green, R., Pearson, N., Sarture, C.,McCubbin, I., Roberts, D., Bradley, E., Steele, D., Ryan, T., Dominguez,R. et the Airborne Visible/Infrared Imaging Spectrometer(AVIRIS) Team (2010). A Method for Quantitative Mapping of Thick Oil Spills Using Imaging Spectroscopy. U.S. Geological Survey Open-File Report 2010$1167,51 \mathrm{p}$.

Fingas, M. F., \& Brown, C. E. (1997). Review of oil spill remote sensing. Spill Science \& Technology Bulletin, 4, 199208.

A. Innman, G. Easson, V. L. Asper, A.-R. Diercks. 2010. 'The Effectiveness of Using MODIS Products to Map Sea Surface Oil', Proc. OCEANS

Khun F., Oppermann K. and Horig B., "Hydrocarbon index an algorithm for hyperspectral detection of hydrocarbons", INT. J. Remote Sensing, vol. 25, N 12, pp 2467-2473, 2004.

Kokaly R., Hoefen T., Livo K., Swayez G., Leifer I., McCubbin I., Eastwood M., Greeen R., Lundeen S., Sarture C., Steele D., Ryan T., Bradley E., Roberts D. and the Airborne Visible/Infrared Imaging Spectrometer (AVIRIS) Team (2010). A Rapid Method for Creating Qualitative Images Indicative of Thick Oil Emulsion on the Ocean's Surface from Imaging Spectrometer Data. U.S. Geological Survey Open-File Report 2010-1107, 16p.

Leifer, Ira; Lehr, William J.; Simecek-Beatty, Debra; Bradley, Eliza; Clark, Roger; Dennison, Philip; Hu, Yongxiang; Matheson, Scott;Jones, Cathleen E.; Holt, Benjamin; Reif, Molly; Roberts, Dar A.; Svejkovsky, Jan; Swayze, Gregg; and Wozencraft, Jennifer, "State of the art satellite and airborne marine oil spill remote sensing: Application to the BP Deepwater Horizon oil spill" (2012). Publications, Agencies and Staff of the U.S. Department of Commerce. Paper 345

Minchew, B., Jones, C. E., and Holt, B., "Polarimetric Analysis of Backscatter From the Deepwater Horizon Oil Spill Using LBand Synthetic Aperture Radar", Accepted for publication in IEEE Transactions on Geoscience and Remote Sensing, 19 pages, 2012

Sicot G., Lennon M., Miegebielle V., Dubucq D., 2014. "Analysis of the reflectance spectra of oil emulsion spilled on the sea surface"', Proc. SPIE 9240, 924007

Skrunes, S., Brekke, C., and Eltoft, T., 2012, "Oil Spill Characterization with Multi-Polarization C- and X-band SAR", In Proc. of IGARSS 2012, Munich, 
Solberg, AH.S., "Remote Sensing of Ocean Oil-Spill Pollution," Proc. IEEE, vol.100, no.10, pp.2931,2945 (2012)

Oscar Garcia-Pineda, Ian MacDonald, Chuanmin $\mathrm{Hu}$, Jan Svejkovsky, Mark Hess, Dmitry Dukhovskoy, Steve Moorey, 2014. Detection and mapping of floating oil emulsions with synthetic aperture radar (sar) imagery. 